\title{
Quantitative EEG in attention-deficit/hyperactivity disorder
}

\section{A companion payment policy review for clinicians and payers}

\author{
Marc R. Nuwer, MD, PhD; Jeffrey Buchhalter, MD, PhD; Katie M. Shepard
}

\begin{abstract}
Quantitative EEG measurement of the scalp vertex theta/beta ratio (TBR) is marketed as a tool for use in the evaluation of patients who may have attentiondeficit/hyperactivity disorder (ADHD). The American Academy of Neurology (AAN) recently assessed the literature about this tool. The assessment urged caution, considering that the TBR remains an investigational research tool at this time. This perspective comments further on that assessment and its rationale, and recommends a perspective for the clinician and payer. Neurol Clin Pract 2016;6:543-548
\end{abstract}

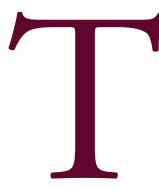

he use of quantitative EEG (QEEG) continues to receive attention as a controversial diagnostic aid for attention-deficit/ hyperactivity disorder (ADHD). For the purposes of this perspective piece, attention-deficit disorder is included in the definition of ADHD.

The QEEG generally considered in the United States is the theta/beta ratio (TBR). TBR is the ratio of the amount of theta activity divided by the amount of beta activity, where both are measured at the scalp vertex site $\mathrm{Cz}$. The ears are linked to use as reference electrode sites for the measurements, so these measurements include the EEG activity from both the scalp vertex and the lower temporal regions. In many studies, the TBR measurement is a single channel EEG based on 1-3 minutes of EEG.

TBR measurement is available in commercial equipment. Commercial units display results as low, moderate, or high TBR without giving specific numeric values or raw EEG displays. The norms are age-adjusted.
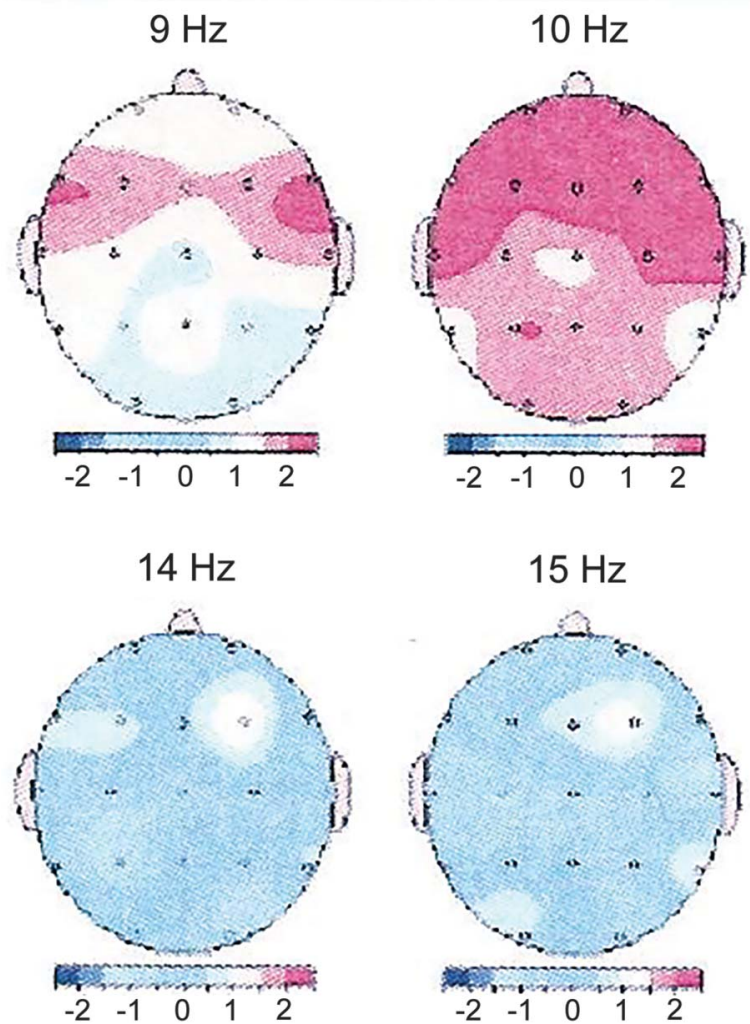

University of California Los Angeles (MRN); University of Calgary (JB), Canada; and American Academy of Neurology (KMS), Minneapolis, MN.

Funding information and disclosures are provided at the end of the article. Full disclosure form information provided by the authors is available with the full text of this article at Neurology.org/cp.

Approved by the Payment Policy Subcommittee on July 15, 2016; by the Medical Economics and Management Committee on August 4, 2016; and by the AAN Board of Directors on August 12, 2016.

Correspondence to: kshepard@aan.com 


\section{The TBR has a dramatic age effect, decreasing markedly as a child ages from childhood toward adulthood.}

\section{American Academy of Neurology practice and advisory findings}

The American Academy of Neurology (AAN) assessment ${ }^{1}$ found a relative lack of support for the use of TBR tests for the diagnosis of ADHD. The 3 conclusions from that assessment are as follows:

- Clinicians should inform patients with suspected ADHD and their families that the combination of TBR and frontal EEG beta power should not replace a standard clinical evaluation.

- There is a risk for substantial harm to patients misdiagnosed with ADHD, given the high false-positive diagnostic rate of TBR and frontal EEG beta power.

- Clinicians should inform patients with suspected ADHD and their families that the TBR should be used neither to confirm an ADHD diagnosis nor to support further testing after a clinical evaluation, unless such diagnostic assessments take place within the limits of a research study.

Although some studies showed that TBR has a relatively high sensitivity and specificity for $\mathrm{ADHD}$, the published literature was inconclusive.

For example, one large recent study ${ }^{2}$ based TBR measurements on 60 seconds of EEG. The gold standard for ADHD was unusual or unclear because patients with the most ADHD symptoms constituted the "ADHD-negative" control group. All patients were children referred to a specialized center for assessment of ADHD. Those considered to have a primary diagnosis of an anxiety, anger, or another disorder along with $\mathrm{ADHD}$ as a secondary diagnosis were considered ADHD-negative for this study, a classification that seemed peculiar because otherwise these patients would have been considered ADHD-positive patients. The classification decision ultimately compromised the gold standard in the study. There was no comparison to other childhood psychiatric or neurologic disorders as controls, and there were no normal controls. The diagnoses for the study were established upon initial referral, not upon follow-up, and the eventual diagnosis was unknown. The cutoff for "abnormal" was set at $1.5 \mathrm{SDs}$ above the mean for age, so that $15 \%$ of the normal population would be expected by chance alone to be falsely positive. The authors were involved with commercialization of this product, which could be viewed as a conflict of interest. It seems wise to wait for further studies from investigators who do not have a commercial conflict of interest, who could run a study with a better gold standard, and in which other disorders and normal controls could be assessed.

Uncertainties abound. Increased theta is a well-known, nonspecific EEG finding common to a wide variety of conditions. Many pathologic conditions cause excess central theta, and even simple drowsiness does so. EEG is subject to normal variant rhythms that are well-known to have no pathologic implications, including benign temporal theta or its central analog the Ciganek rhythm. Temporal theta could show up in these $\mathrm{Cz}$ channels because the ear reference electrodes are active and will detect temporal rhythms. For all these reasons, increased central theta or TBR is a suspect sign on which to base a diagnosis of ADHD.

\section{Background about ADHD and the TBR}

Increased central theta in children with behavioral disorders was reported in the 1930s. ${ }^{3}$ Studies in the 1960s and 1970s confirmed excess theta activity in some childhood behavioral disorders. ${ }^{4}$ The push to use a TBR as a diagnostic test began more than 15 years ago. Initial studies $^{5}$ described good sensitivity, specificity, and reliability for TBR as a diagnostic tool. 


\section{The AAN Guideline recommends that the TBR
test is not yet ready for routine clinical use.}

TBR in children correlated with behavioral measures of impulsivity and inhibition both in ADHD and normal children. ${ }^{6}$ TBR findings in adults correlated with response times that were used as a marker for attention. ${ }^{7}$

However, problems began to appear with the accuracy of TBR when attempted as a diagnostic test. Attempts to reproduce earlier studies found only a $63 \%$ sensitivity and $58 \%$ specificity and even worse diagnostic accuracies for TBR in diagnosis of ADHD. ${ }^{8-10}$ The TBR has a dramatic age effect, decreasing markedly as a child ages from childhood toward adulthood. ${ }^{10}$ TBR results differed depending on whether the child had hyperactive or inattentive subtype.

One study evaluated TBR correlation with ADHD symptoms in 562 patients and 309 control subjects. ${ }^{11}$ Results showed a correlation of $r=0.10$ for children and $r=-0.14$ for adults, specifically a low correlation for younger children, poor correlation for adolescents, and the inverse correlation for adults.

TBR diagnostic effect size decreased corresponding to the year of a study's publication. ${ }^{12}$ The report showed that the enthusiasm of a notable TBR effect by initial investigators was tempered by a lack of confirmation in follow-up studies, so that the effect size decreased in proportion to the calendar year in which the study was published. Original studies showed an effect, and more recent studies failed to confirm such a distinct TBR diagnostic effect (figure).

Overall, these results suggest several conclusions: TBR may be increased in some children with ADHD. This effect may be seen only in one or another subtype (e.g., inattentive). The effect may disappear in older children and adolescents. The effect may actually be reversed in adults. TBR may not differentiate well between ADHD and normal controls, depending on which study is consulted. The effect in other disorders is unknown. The effect with drowsiness and medications is uncertain. False-positive and false-negative results may be common.

Figure Meta-analysis of 9 studies of patients with attention-deficit/hyperactivity disorder (ADHD) vs controls
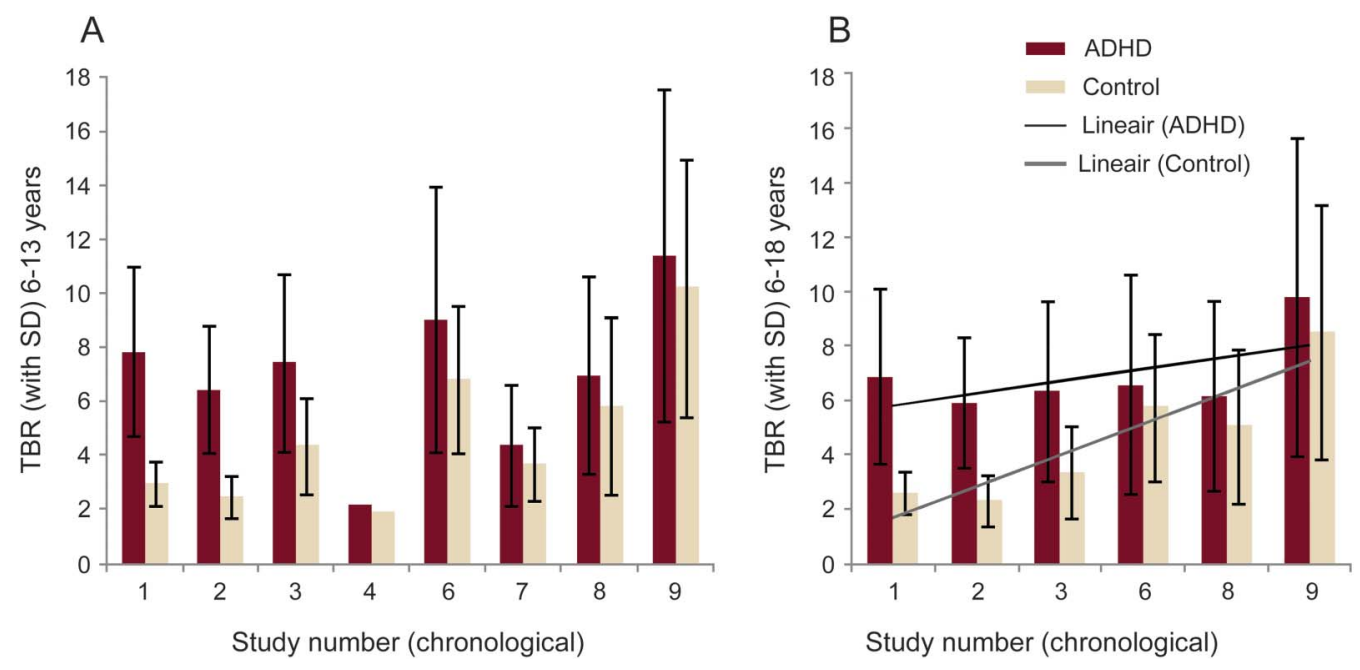

Two age groups are presented: younger children (age 6-13; A) and all children (age 6-18; B). Theta/beta ratio (TBR) means and SDs are presented. The 9 studies are shown chronologically as published. Note how the differences between ADHD and controls narrowed over time, and how much scatter is seen in TBR measurements among studies of younger children. From Arns et al. ${ }^{12}$ 
Table Current payer coverage policies

\begin{tabular}{|c|c|c|c|}
\hline Payer & Policy title & Coverage policy current & Next review date \\
\hline HealthNet & & $\begin{array}{l}\text { HealthNet considers quantitative EEG (QEEG) (brain } \\
\text { mapping) investigational for the following indications, } \\
\text { due to lack of evidence in the peer review literature } \\
\text { demonstrating its effectiveness: } \\
\text { 1. Alcoholism } \\
\text { 2. Attention disorders } \\
\text { 3. Depression } \\
\text { 4. Drug abuse } \\
\text { 5. Fibromyalgia } \\
\text { 6. Learning disability } \\
\text { 7. Migraine headache } \\
\text { 8. Minor or moderate head injury } \\
\text { 9. Parkinson disease } \\
\text { 10. Postconcussion syndrome } \\
\text { 11. Schizophrenia } \\
\text { 12. Tinnitus }\end{array}$ & Unspecified \\
\hline Cigna & $\begin{array}{l}\text { Attention-deficit/hyperactivity } \\
\text { disorder (ADHD): Assessment } \\
\text { and treatment }{ }^{16}\end{array}$ & $\begin{array}{l}\text { Cigna does not cover the following procedures/services, } \\
\text { because each is considered experimental, investigational, } \\
\text { or unproven for the assessment and/or treatment of } \\
\text { ADHD (these lists may not be all-inclusive): } \\
\text { Assessment: } \\
\text { - Actometer } \\
\text { - Computerized EEG (e.g., brain mapping, neurometrics, } \\
\text { or QEEG, neuropsychiatric EEG-based assessment aid } \\
\text { [NEBA] system) } \\
\text { - Computerized tests of attention and vigilance } \\
\text { - Event-related potentials (i.e., evoked potential studies) } \\
\text { - Hair analysis } \\
\text { - Neuroimaging (e.g., CT, MRI, PET, and SPECT) } \\
\text { - Quotient ADHD test/system } \\
\text { There is insufficient evidence in the medical literature to } \\
\text { support the use of computerized methods of EEG (e.g., brain } \\
\text { mapping, neurometrics, or QEEG, NEBA system) in the } \\
\text { assessment of ADHD }\end{array}$ & January 15, 2017 \\
\hline BCBS MN & $\begin{array}{l}\text { Medical and behavioral health } \\
\text { policy } \\
\text { Section: Behavioral Health } \\
\text { QEEG or brain mapping for mental } \\
\text { health or substance-related } \\
\text { disorders }\end{array}$ & $\begin{array}{l}\text { QEEG or brain mapping is considered investigative for } \\
\text { clinical use in all other disorders included in the most } \\
\text { current version of the American Psychiatric Association's } \\
\text { Diagnostic and Statistical Manual of Mental Disorders, } \\
\text { including but not limited to the following: } \\
\text { A. Learning disability } \\
\text { B. Attention disorders } \\
\text { C. Schizophrenia } \\
\text { D. Depression } \\
\text { E. Substance-related disorders }\end{array}$ & Unspecified \\
\hline
\end{tabular}

\section{Clinical lessons}

The AAN Guideline recommends that the TBR test is not yet ready for routine clinical use. Rather, it is best used in formal structured research investigations that may better define its role, if any. A similar recommendation was reached by a group of psychology QEEG experts. ${ }^{13}$ That group considered that TBR cannot be used to diagnose or rule out ADHD, and it does not replace a regular clinical examination. 
Payers have taken a similar position (table). They consider the use of any QEEG for ADHD investigational or experimental.

The Food and Drug Administration, ${ }^{14}$ while giving its approval for commercial marketing, cautioned that TBR must be used only upon a physician's order, by a medical professional qualified and experienced to diagnose ADHD, only after a traditional evaluation, and not as a stand-alone test. It cannot be used if a routine EEG has shown any abnormalities, or if the patient has a history of seizures, or is on any seizure medication. Then a low TBR value would suggest that the clinician should check for other disorders that might have produced the patient's symptoms.

The clinician should exercise caution in use and interpretation of TBR results. Meanwhile, we await further research by investigators who are not affiliated with companies marketing these services and devices.

\section{REFERENCES}

1. Gloss D, Varma JK, Nuwer MR. Practice advisory: the utility of EEG theta/beta power ratio in ADHD diagnosis: report of the Guideline Development, Dissemination, and Implementation Subcommittee of the American Academy of Neurology. Neurology 2016;87:2375-2379.

2. Snyder SM, Rugino TA, Hornig M, Stein MA. Integration of an EEG biomarker with a clinician's ADHD evaluation. Brain Behav 2015;5:e00330.

3. Jasper H, Solomon P, Bradley C. Electroencephalographic analyses of behavior problem children. Am J Psychiatry 1938;95:641.

4. Satterfield JH, Lesser LI, Saul RE, Cantwell DP. EEG aspects in the diagnosis and treatment of minimal brain dysfunction. Ann NY Acad Sci 1973;205:274-282.

5. Monastra VJ, Lubar JF, Linden M. The development of a quantitative electroencephalographic scanning process for attention deficit-hyperactivity disorder: reliability and validity studies. Neuropsychology 2001;15:136-144.

6. Williams LM, Hermens DF, Thein T, et al. Using brain-based cognitive measures to support clinical decisions in ADHD. Pediatr Neurol 2010;42:118-126.

7. Van Dongen-Boomsma M, Lansbergen MM, Bekker EM, et al. Relation between resting EEG to cognitive performance and clinical symptoms in adults with attention-deficit/hyperactivity disorder. Neurosci Lett 2010;469:102-106.

8. Ogrim G, Kropotov J, Hestad K. The quantitative EEG theta/beta ration in attention deficit/ hyperactivity disorder and normal controls: sensitivity, specificity, and behavioral correlates. Psychiatry Res 2012;198:482-488.

9. Liechti MD, Valko L, Müller UC, et al. Diagnostic value of resting electroencephalogram in attention-deficit/hyperactivity disorder across the lifespan. Brain Topogr 2013;26:135-151.

10. Buyck I, Wieserma JR. Resting electroencephalogram in attention deficit hyperactivity disorder: developmental course and diagnostic value. Psychiatry Res 2014;216:391-397.

11. Loo SK, Cho A, Hale TS, McGough J, McCracken J, Smalley SL. Characterization of the theta to beta ratio in ADHD: identifying potential sources of heterogeneity. J Atten Disord 2013;17:384-392.

12. Arns M, Conners CK, Kraemer HC. A decade of EEG theta/beta ratio research in ADHD: a metaanalysis. J Atten Disord 2013;17:374-383.

13. Arns M, Loo SK, Sterman MB, et al. Editorial Perspective: how should child psychologists and psychiatrists interpret FDA device approval? Caveat emptor. J Child Psychol Psychiatr 2016;57:656-658.

14. The Department of Health \& Human Services, Food and Drug Administration. Letter to NEBA Health, LLC. Re: K112711 Neuropsychiatric EEG-based assessment aid for ADHD (NEBA) System. 2013. Available at: https://www.accessdata.fda.gov/cdrh_docs/pdf11/K112711.pdf. Accessed July 29, 2016.

15. Aetna Quantitative EEG (Brain Mapping) Policy Number 0221. Available at: aetna.com/cpb/medical/ data/200_299/0221.html. Accessed July 29, 2016.

16. Cigna Attention-Deficit/Hyperactivity Disorder (ADHD): Assessment and Treatment Policy Number 0231. Available at: cignaforhcp.cigna.com/public/content/pdf/coveragePolicies/medical/mm_0231_ coveragepositioncriteria_adhd_assessment_and_treatment.pdf. Accessed July 29, 2016.

Received August 20, 2015. Accepted in final form August 2, 2016.

\section{AUTHOR CONTRIBUTIONS}

All authors contributed to drafting/revising the manuscript, information and data acquisition, and critical revision of the manuscript for intellectual content. 


\section{ACKNOWLEDGMENT}

The authors thank members of the American Academy of Neurology Payment Policy Subcommittee as well as the authors of the AAN's guideline document for their support of concept and review of early versions of the manuscript.

\section{STUDY FUNDING}

No targeted funding reported.

\section{DISCLOSURES}

M.R. Nuwer has received travel reimbursement to serve as a representative at the AMA, CPT, and RUC meetings on behalf of the American Academy of Neurology and American Clinical Neurophysiology Society; serves on the editorial boards of Neurology ${ }^{\circledR}$ Clinical Practice, Journal of Clinical Neurophysiology, and Practical Neurology and as Honorary Consulting Editor for Clinical Neurophysiology; receives publishing royalties for Intraoperative Neurophysiologic Monitoring (Cambridge University Press, 2008); serves as laboratory medical director for SleepMed, where he advises on and reviews laboratory procedures; receives research support from NIH/National Institute of Neurological Disorders and Stroke and CDMRP; receives stock, stock options, and/or Board of Directors compensation from Corticare, which outsources ICU EEG monitoring; and has served as an expert in legal proceedings related to QEEG. J. Buchhalter serves on scientific advisory boards for NIH, NINDS, Charlie Foundation, and IDIC 15; has received funding for travel and/or speaker honoraria from AAN, Eisai Ltd, Lundbeck, and Upsher-Smith; served on the editorial advisory board for Clinical Neurology News; has served as a consultant to Lundbeck, Inc., Eisai Ltd., UCB, and Upsher-Smith; and receives research support from Alberta Health Services. K. Shepard serves as Director of Medical Economics for the American Academy of Neurology. Full disclosure form information provided by the authors is available with the full text of this article at Neurology.org/cp.

\section{Related articles from AAN physician and patient resources}

\section{Neurology ${ }^{\circledR} \quad$ Neurology.org}

Variations in EEG discharges predict ADHD severity within individual Smith-Lemli-Opitz patients

July 8, 2014;83:151-159.

\section{Continuum ${ }^{\circledR}$ - ContinuumJournal.com}

Neurodevelopmental Behavioral and Cognitive Disorders June 2015;21:690-714.

\section{Neurology Now ${ }^{\circledR}$ - Neurologynow.com}

How does a neurologist decide whether to give a drug for ADHD to children? August/September 2014;10:47. 


\section{Neurology ${ }^{\circ}$ Clinical Practice}

\section{Quantitative EEG in attention-deficit/hyperactivity disorder: A companion payment policy review for clinicians and payers \\ Marc R. Nuwer, Jeffrey Buchhalter and Katie M. Shepard}

Neurol Clin Pract 2016;6;543-548 Published Online before print November 4, 2016

DOI 10.1212/CPJ.0000000000000308

This information is current as of November 4, 2016

$\begin{array}{ll}\begin{array}{l}\text { Updated Information \& } \\ \text { Services }\end{array} & \begin{array}{l}\text { including high resolution figures, can be found at: } \\ \text { http://cp.neurology.org/content/6/6/543.full.html }\end{array} \\ \text { References } & \text { This article cites } 13 \text { articles, } 0 \text { of which you can access for free at: } \\ & \text { http://cp.neurology.org/content/6/6/543.full.html\#\#ref-list-1 } \\ \text { Subspecialty Collections } & \text { This article, along with others on similar topics, appears in the } \\ & \text { following collection(s): } \\ & \text { ADHD } \\ & \text { http://cp.neurology.org//cgi/collection/adhd } \\ & \text { All Practice Management } \\ & \text { http://cp.neurology.org//cgi/collection/all_practice_management } \\ & \text { Insurance } \\ \text { http://cp.neurology.org//cgi/collection/insurance } & \\ & \text { Information about reproducing this article in parts (figures,tables) or in } \\ & \text { its entirety can be found online at: } \\ \text { http://cp.neurology.org/misc/about.xhtml\#permissions } & \text { Information about ordering reprints can be found online: } \\ \text { Permissions \& Licensing } & \text { http://cp.neurology.org/misc/addir.xhtml\#reprintsus }\end{array}$

Neurol Clin Pract is an official journal of the American Academy of Neurology. Published continuously since 2011, it is now a bimonthly with 6 issues per year. Copyright $\odot 2016$ American Academy of Neurology. All rights reserved. Print ISSN: 2163-0402. Online ISSN: 2163-0933.

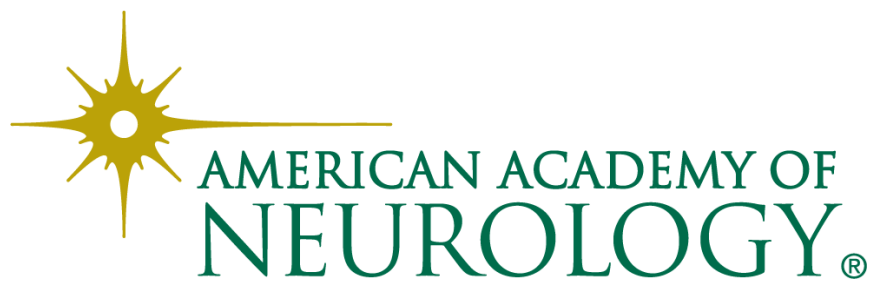

